\title{
Electrical Properties and Electromagnetic Interference Shielding Effectiveness of Interlayered Systems Composed by Carbon Nanotube Filled Carbon Nanofiber Mats and Polymer Composites
}

\author{
Claudia Angélica Ramírez-Herrera ${ }^{1}{ }^{1}$, Homero Gonzalez ${ }^{2}$, Felipe de la Torre $^{3}$, Laura Benitez ${ }^{3}$, \\ José Gerardo Cabañas-Moreno ${ }^{1}$ and Karen Lozano ${ }^{2, *}$ \\ 1 Programa de Doctorado en Nanociencias y Nanotecnología, CINVESTAV, \\ Av. Instituto Politécnico Nacional 2508, Cd. de México 07360, México; \\ caramirezh@cinvestav.mx (C.A.R.-H.); jcabanasm@cinvestav.mx (J.G.C.-M.) \\ 2 Mechanical Engineering Department, The University of Texas Rio Grande Valley, 1201 West University \\ Drive, Edinburg, TX 78539, USA; homero.gonzalez01@utrgv.edu \\ 3 Electrical Engineering Department, The University of Texas Rio Grande Valley, 1201 West University Drive, \\ Edinburg, TX 78539, USA; felipe.delatorre01@utrgv.edu (F.d.1.T.); laura.benitez@utrgv.edu (L.B.) \\ * Correspondence: karen.lozano@utrgv.edu; Tel.: +1-956-665-7020
}

Received: 30 December 2018; Accepted: 5 February 2019; Published: 10 February 2019

check for updates

\begin{abstract}
The demand for multifunctional requirements in aerospace, military, automobile, sports, and energy applications has encouraged the investigation of new composite materials. This study focuses on the development of multiwall carbon nanotube (MWCNT) filled polypropylene composites and carbon nanofiber composite mats. The developed systems were then used to prepare interlayered composites that exhibited improved electrical conductivity and electromagnetic interference (EMI) shielding efficiency. MWCNT-carbon nanofiber composite mats were developed by centrifugally spinning mixtures of MWCNT suspended in aqueous poly(vinyl alcohol) solutions. The developed nanofibers were then dehydrated under sulfuric acid vapors and then heat treated. Interlayered samples were fabricated using a nanoreinforced polypropylene composite as a matrix and then filled with carbon fiber composite mats. The in-plane and through-plane electrical conductivity of an eight-layered flexible carbon composite $\left(0.65 \mathrm{~mm}\right.$ thick) were shown to be 6.1 and $3.0 \times 10^{-2}$ $\mathrm{S} \cdot \mathrm{cm}^{-1}$, respectively. The EMI shielding effectiveness at $900 \mathrm{MHz}$ increased from $17 \mathrm{~dB}$ for the one-layered composite to $52 \mathrm{~dB}$ for the eight-layered composite. It was found that the reflection of the electromagnetic waves was the dominating mechanism for EMI shielding in the developed materials. This study opens up new opportunities for the fabrication of novel lightweight materials that are to be used in communication systems.
\end{abstract}

Keywords: interlayered composites; forcespinning ${ }^{\circledR}$; carbon nanofibers; carbon nanotubes; shielding effectiveness

\section{Introduction}

Conventional reinforced polymer composites have displayed potential for their use in aerospace, military, automobile, sports, and energy applications; however, the demand for multifunctional properties has encouraged the investigation of new materials. In recent years, numerous studies on the development of advanced polymer composites with improved electrical, mechanical, thermal, and electromagnetic interference (EMI) shielding properties have been conducted [1-4]. Carbon nanomaterials, such as carbon nanotubes (CNT) [5-7], carbon nanofibers (CNF) [8,9], 
and graphene $[10,11]$ have been considered as ideal reinforcements for polymer composites due to their exceptional electrical and thermophysical properties coupled with their high aspect ratio, high strength, and stiffness, which leads to significant enhancements in electrical conductivity, mechanical stability, and EMI shielding. The properties of these attractive carbon-based systems have been for the most part independently evaluated. As the potential for practical applications is being reported, the development of systems with multifunctional properties has attracted considerable interest from the scientific community in synergistically improving thermal, electrical, and structural properties [12-16].

An innovative way to develop multifunctional composite materials is by developing interlayered composites that incorporate dissimilar architectures, mainly nonwoven CNF mats, woven carbon fibers (CF) fabrics, and CNT or CNF based buckypaper (BP) into polymer matrices using diverse fabrication methods. A wide variety of studies that focused on the electrical, mechanical, and electromagnetic interference shielding efficiency of interlayered composites have been reported [17-25]. For instance, $\mathrm{Xu}$ et al. [17] proposed a new method of depositing continuous CNT films onto CF fabrics using the floating catalyst chemical vapor deposition (FCCVD) method. The dry fabric was infiltrated into an epoxy resin and stacking twelve plies of the impregnated materials formed a laminate composite. They reported that the flexural strength and interlaminar shear strength of the composite containing $0.22 \mathrm{wt}$ \% of CNT (per layer of carbon fiber fabric) increased by $16 \%$ and $21 \%$, respectively, when compared to laminated composites without the added CNT. Moreover, the surface (in-plane) and volumetric (through-plane) electrical conductivity were also improved, $166 \%$ and 150\%, respectively, upon the deposition of CNT (1.09 wt.\%) on the CF fabrics.

Wang et al. [18] reported the preparation of $\mathrm{BP} / \mathrm{CF}$ hybrid composites by adding BP between the CF plies using CF prepregs. Both, the surface and volumetric electrical conductivities exhibited significant improvements upon the addition of 7.99 wt.\% of CNT. In another study, the CNT/CF/poly(ether-ether-ketone) (PEEK) multiscale composites that were prepared by directly spraying acid-treated CNT onto CF/PEEK prepregs were developed [19]. The resultant prepreg layers were stacked and consolidated by compression molding. The laminated composites showed enhanced mechanical properties with the presence of $0.5 \mathrm{wt} . \%$ of $\mathrm{CNT}$, which was attributed to the mechanical anchoring effect of the CNT, improving fiber-matrix interactions. The electrical conductivity of the composites was also improved by the formation of the typical conductive network.

Several studies have also focused on the EMI shielding of these composites, for example, Park et al. [23] reported the preparation of laminates using multiple layers of BP with different stacking sequences and employing two types of dielectric materials (epoxy resin and polyethylene (PE)). $\mathrm{BP} / \mathrm{PE}$ single-layer composites exhibited shielding effectiveness (SE) within the 20-60 dB range, and the increases were proportional to the conductivity that was recorded by the original BP used. The increase in the number of BP conducting layers and dielectric material coupled with the architecture of the system increased the electromagnetic interference shielding effectiveness (EMI SE) from $45 \mathrm{~dB}$ to close to $100 \mathrm{~dB}$. In another study, Silveira et al. [24] developed multifunctional composites that were based on epoxy resin/glass fiber woven fabric prepregs and non-woven CF/Ni veils using compression molding. The developed laminated composites resulted in a high reflection of incident microwaves, being 91.4-100\%. Composites of continuous carbon fibers (CCF) that were arranged on poly(ethylene terephthalate) (PET)-nonwoven fabric substrates using different orientations, and the number of layers have also been studied [25]. At high frequency (750 MHz-1.5 GHz), the orientation of the CCF showed a greater influence on the shielding performance than the number of layers. A three-layer composite with orientations between layer and layer of $0^{\circ}-0^{\circ}-45^{\circ}$ reached the highest value of SE, $60 \mathrm{~dB}$ at $1.0 \mathrm{GHz}$.

Existent literature shows important improvements in the search to find materials with promising practical applications where the needed properties, such as electrical conductivity, shielding of electromagnetic interference, structural stability, and lightweight, are adequately complemented with the ease of fabrication and cost-effectiveness. The above-mentioned systems are highly desired in important applications, for example, in the development of rigid wall shelters for defense-related 
applications and in novel cable systems (uses ranging from everyday applications to aerospace applications). This study effectively addresses the needs that are mentioned above by developing nonwoven carbon composite mats, taking advantage of the Forcespinning ${ }^{\circledR}$ method that uses centrifugal force to spin fine fibers (nano-, submicron-, and single digit fibers) at industrial scales, (hundreds of meters per minute) [26,27]. The developed multiwall carbon nanotube (MWCNT) filled carbon nanofiber mats were stacked using a matrix that was composed of MWCNT reinforced polypropylene. The morphology, electrical properties, and EMI SE of the developed composites were evaluated.

\section{Materials and Methods}

\subsection{Materials}

Poly(vinyl alcohol) (PVA) (Mw $\approx 85,000-124,000)$, with a viscosity of $27 \mathrm{cP}$ and hydrolysis grade of $96 \%$, was obtained from Kuraray, Inc., (Houston, TX, USA) and was used as received. Commercial grade polypropylene, PP $4280 \mathrm{~W}$ Impact copolymer (supplied by Total Petrochemicals, Houston, TX, USA), with a melt flow index $=1.3 \mathrm{~g} / 10 \mathrm{~min}$, was used as the matrix. MWCNT (cat. number 773840 from Sigma-Aldrich, St. Louis, MO, USA), with a purity $\geq 98 \%$, average outside diameter of $10 \mathrm{~nm}$, and length of 3-6 $\mu \mathrm{m}$ were used as one of the electrically conductive fillers. Sulfuric acid (reagent grade) was purchased from Sigma-Aldrich.

\subsection{Production of MWCNT Filled Carbon Nanofiber Mats Using the Forcespinning ${ }^{\circledR}$ Method}

Solutions containing PVA and MWCNT in distilled water were prepared. The MWCNT $(0.05$ and $0.1 \mathrm{wt} . \%$ ) were dispersed in distilled water in an ultrasonic bath for $15 \mathrm{~min}$, and were then mechanically agitated for $15 \mathrm{~min}$. Subsequently, the PVA (10 wt.\%) was added to the MWCNT dispersion. The resulting solutions were subjected to magnetic stirring at $75{ }^{\circ} \mathrm{C}$ for $2.5 \mathrm{~h}$ in an oil bath. The solutions were maintained under magnetic stirring at room temperature for $24 \mathrm{~h}$ and then subsequently fed into a two-nozzle spinneret and spun at $9000 \mathrm{rpm}$ for $3 \mathrm{~min}$ using the Cyclone L-1000 M from Fiberio Technology Corp. (Mission, TX, USA). The obtained nanofibers were collected in $11 \mathrm{~cm} \times 11 \mathrm{~cm}$ hollow metal frames. This procedure was repeated until the desired thickness, based on grams per square meter (GSM), was obtained. The collected mats were dehydrated by exposure to sulfuric acid vapors, the mats were placed $5 \mathrm{~cm}$ above a heated bath of sulfuric acid whose temperature varied from 180 up to $280^{\circ} \mathrm{C}$. The treated mats were subsequently washed with distilled water to remove the remaining acid and then dried overnight at room temperature. The samples were then subjected to a carbonization process that consisted of a stabilization procedure at $240^{\circ} \mathrm{C}$ for $15 \mathrm{~min}$ in air atmosphere, followed by ramping up to $1000^{\circ} \mathrm{C}$ at a heating rate of $3^{\circ} \mathrm{C} \mathrm{min}^{-1}$ under a nitrogen atmosphere [28]. The areal density for the developed MWCNT reinforced carbon nanofiber nonwoven mats was 42 GSM.

\subsection{Preparation of Nanoreinforced Polymer Composite Sheets (NRPCS)}

Polypropylene pellets were mixed with MWCNT (15 wt.\% or 7.07 vol.\%) at $190{ }^{\circ} \mathrm{C}, 90 \mathrm{rpm}$ for 30 min using a HAAKE Rheomix mixer on a HAAKE Rheocord Torque Rheometer (Thermo Fisher Scientific Inc. (Karlsruhe, Germany). After mixing, the composite was compression molded at $200^{\circ} \mathrm{C}$ to form sheets of $0.1 \mathrm{~mm}$ in thickness. The NRPCS were used as the matrix for the MWCNT filled carbon nanofiber mats.

\subsection{Fabrication of Interlayered Composites (IC)}

Figure 1a depicts the schematics of the process that was used to fabricate the interlayered composites. Figure $1 \mathrm{~b}$ shows digital images of the spun, dehydrated, and carbonized fiber mats. Figure 1c shows images of the MWCNT reinforced polymeric composite (NRPC), while Figure 1d shows a one-layer MWCNT filled carbon nanofiber mat with one layer of NRPCS. As shown in 
Figure 1a, MWCNT filled carbon nanofiber mats $(0.1 \mathrm{~mm}$ thick) and NRPCS were cut in circles of $3 \mathrm{~cm}$ in diameter and then stacked into a metal mold. The lay-up sequence consisted in alternating one to eight layers of the MWCNT filled carbon nanofiber mats between the layers of the polymer composite sheets. The stacked multilayers were compression-molded at $200{ }^{\circ} \mathrm{C}$ and $42 \mathrm{MPa}$ for $10 \mathrm{~s}$. To prevent the composite from sticking to the compression mold, Mylar sheets were placed on each side of the sample. The final thicknesses of the interlayered composites were $0.1,0.16,0.3$, and $0.65 \mathrm{~mm}$ for the systems with one, two, four, and eight layers, respectively. Table 1 shows a summary of the overall characteristics for the developed samples.

As can be observed from Table 1, the density of interlayered composites diminishes as the number of layers of MWCNT filled carbon nanofiber mats is increased. Additionally, it is noted that by increasing the number of layers, the total content of carbon matrix and local content of MWCNT is augmented, whereas the total content of PP diminishes given that the volume that is occupied by the carbon nanofiber mats is higher than the NRPCS in the interlayered systems. The interlayered composite with the higher numbers of layers (eight) is composed of $18 \mathrm{wt} . \%$ (43 vol.\%) carbon content, 12 wt.\% (9 vol.\%) MWCNT, and 70 wt.\% (48 vol.\%) of PP.
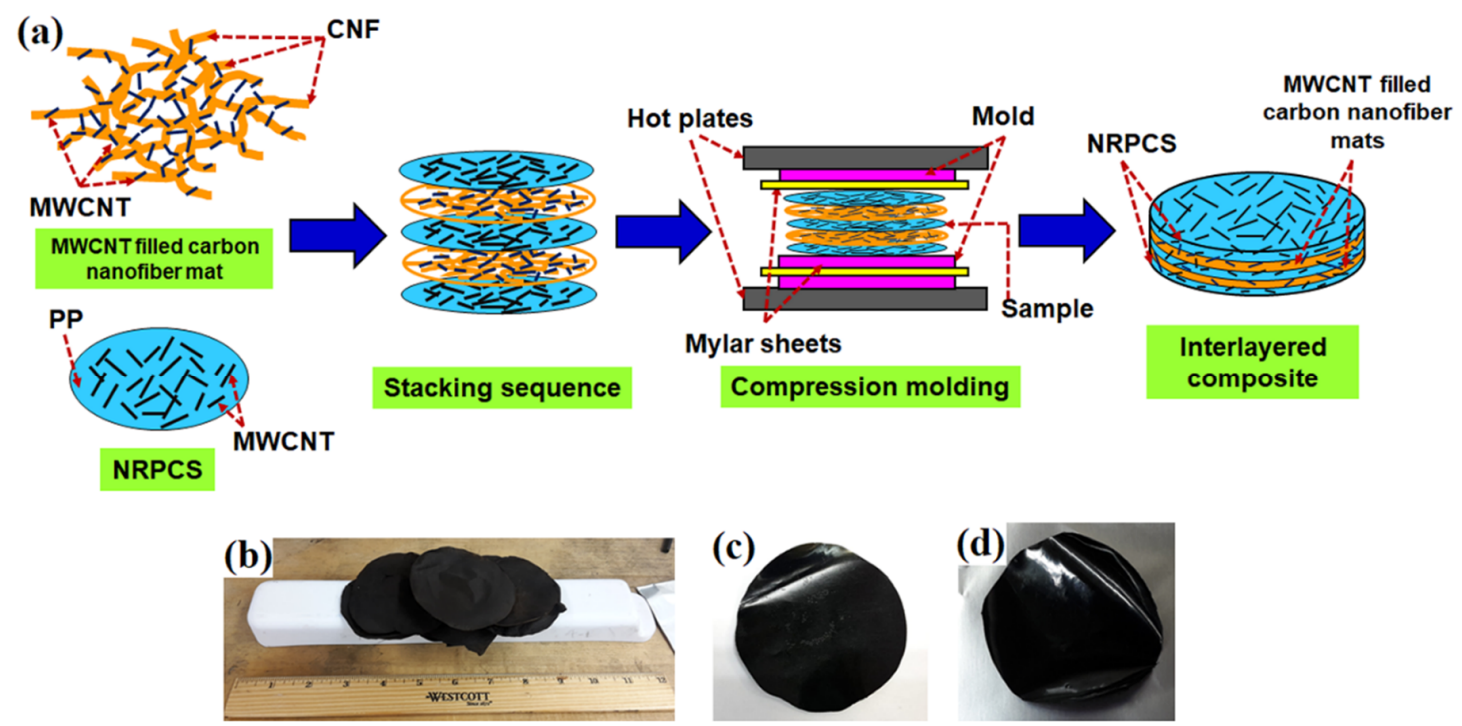

Figure 1. (a) Schematic representation of the fabrication process of interlayered composites; Digital pictures of (b) MWCNT filled carbon nanofiber mats; (c) NRPCS used as starting materials; and, (d) a resultant one-layer interlayered flexible composite. 
Table 1. General characteristics of the developed samples.

\begin{tabular}{|c|c|c|c|c|c|c|c|c|c|c|}
\hline $\begin{array}{r}\text { ID Sample } \\
\text { Parameter }\end{array}$ & CNF Mat & CNF-0.05MWCNT & CNF-0.1MWCNT & NRPCS & IC $-1-0^{2,3}$ & IC-1-0.05 & IC-1-0.1 & IC-2-0.1 & IC-4-0.1 & IC-8-0.1 \\
\hline Thickness (mm) & 0.11 & 0.09 & 0.09 & 0.13 & 0.10 & 0.10 & 0.10 & 0.16 & 0.30 & 0.65 \\
\hline Density $\left(\mathrm{g} \cdot \mathrm{cm}^{-3}\right)$ & 0.33 & 0.30 & 0.28 & 0.99 & 0.79 & 0.79 & 0.78 & 0.73 & 0.70 & 0.68 \\
\hline CNF (wt.\%) & 100 & 99.9 & 99.9 & - & 12.5 & 11.2 & 10.6 & 13.9 & 16.2 & 17.7 \\
\hline CNF (vol.\%) & 100 & 99.9 & 99.9 & - & 29.8 & 29.5 & 29.6 & 36.4 & 40.7 & 43.3 \\
\hline MWCNT in CNF (wt.\%) & - & 0.05 & 0.1 & 15 & - & $6 \times 10^{-3}$ & $1.1 \times 10^{-2}$ & $1.4 \times 10^{-2}$ & $1.6 \times 10^{-2}$ & $1.8 \times 10^{-2}$ \\
\hline MWCNT in CNF (vol.\%) & - & 0.01 & 0.02 & 7.1 & - & $1.4 \times 10^{-2}$ & $2.9 \times 10^{-2}$ & $3.6 \times 10^{-2}$ & $4.1 \times 10^{-2}$ & $4.3 \times 10^{-2}$ \\
\hline MWCNT TC ${ }^{1}$ (wt. $\left.\%\right)$ & - & - & - & - & 13.1 & 13.3 & 13.4 & 13 & 12.6 & 12.4 \\
\hline MWCNT TC (vol.\%) & - & - & - & - & 10.5 & 10.6 & 10.6 & 9.6 & 8.9 & 8.5 \\
\hline PP TC (wt.\%) & - & - & - & 85 & 74.4 & 75.4 & 76 & 73.2 & 71.2 & 70 \\
\hline PP TC (vol.\%) & - & - & - & 92.9 & 60 & 60 & 60 & 54.1 & 50.4 & 48.2 \\
\hline
\end{tabular}

${ }^{1}$ TC-Total Content, ${ }^{2}$ IC - Interlayered composite, ${ }^{3}$ IC — \# layers- wt.\% MWCNT content in the CNF mat. 


\subsection{Characterization}

The morphology of the samples was analyzed while using a field-emission scanning electron microscope (FE-SEM) under an acceleration voltage of $1.0 \mathrm{kV}$ (Sigma VP, Carl Zeiss, Jena, Germany). A statistical analysis of fiber diameter was conducted using Image J software, k1.45 version, National Institutes of Health (NIH), Bethesda, MD, USA. At least ten different SEM micrographs were used to determine the fiber diameters from at least 100 fibers. The mean fiber diameter and the histograms were generated using Minitab ${ }^{\circledR} 17$ Statistical Software (State College, PA, USA). Measurements of the surface resistivity of MWCNT filled carbon nanofiber mats, and interlayered composites on circular specimens of $3 \mathrm{~cm}$ in diameter and thicknesses from $0.1-0.65 \mathrm{~mm}$, were obtained while using an R-CHEK RC2175 four-point probe surface resistivity meter (EDTM, Inc., Toledo, OH, USA) at room temperature. The average value of ten measurements at different locations in each sample was taken as the sheet resistance $\left(R_{\mathrm{s}}\right.$, in $\left.\Omega / \mathrm{sq}\right)$ of the composite. Values of in-plane electrical conductivity $\left(\sigma_{\mathrm{i}}\right.$, in $\left.\mathrm{S} \cdot \mathrm{cm}^{-1}\right)$ were obtained from the sheet resistance and the thickness $(t$ in $\mathrm{cm})$ of the sample, as shown in Equation (1):

$$
\sigma_{i}=\frac{1}{R_{s} t}
$$

The through-plane electrical conductivity $\left(\sigma_{t}, \mathrm{~S} \cdot \mathrm{cm}^{-1}\right)$ was determined by pressing the samples in between cooper electrodes with an effective area of $2.04 \mathrm{~cm}^{2}$ and using the Equation (2):

$$
\sigma_{t}=\frac{t}{A R}
$$

where $t$ is the thickness of the sample $(\mathrm{cm}), A$ is the effective area of the measuring electrodes $\left(\mathrm{cm}^{2}\right)$, and $R$ is the measured resistance of the sample $(\Omega)$.

The EMI SE was measured at room temperature using an in-house manufactured coaxial flange fixture [29] that was connected to a Hewlett-Packard 8712C network analyzer (Palo Alto, CA, USA) that operates in a frequency test range of 0.3 to $1300 \mathrm{MHz}$. The measurements were conducted following a procedure that was described by Vasquez et al. [29]. The measurements require two samples: a reference specimen and a load specimen. Figure 2 shows the dimensions of the reference and load specimens. Each specimen was held between the two coaxial flanged fixtures and the values that were obtained from the analyzer were given in $\mathrm{dB}$. The total EMI SE is the ratio of incident to transmitted energy, which can be expressed as [30-34]:

$$
S E_{T}=10 \log \frac{P_{1}}{P_{2}}
$$

where $P_{1}$ is the received power density with the material present (load specimen) and $P_{2}$, is the received power density without the material present (reference specimen).
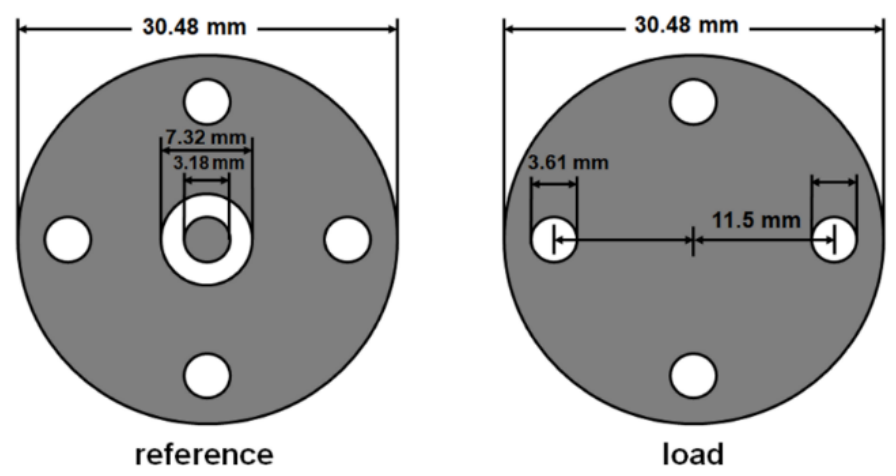

Figure 2. Fixture configuration for testing of electromagnetic interference (EMI) shielding effectiveness [29]. 
The total experimental SE ( $\left.S E_{\text {Total }}\right)$ is the sum of the shielding by reflection $\left(S E_{\text {ref }}\right)$ and absorption $\left(S E_{\mathrm{abs}}\right)$, involving the contribution of multiple reflections $\left(S E_{\mathrm{mr}}\right)$, which can be obtained based on experimental parameters, as shown [31-33]:

$$
\begin{gathered}
S E_{\mathrm{Total}}=S E_{\mathrm{ref}}+S E_{\mathrm{abs}}+S E_{\mathrm{mr}} \\
S E_{\mathrm{ref}}=-10 \log (1-R) \\
S E_{\mathrm{abs}}=-10 \log (1-A)=-10 \log \left(\frac{T}{1-R}\right)
\end{gathered}
$$

where $R, A$, and $T$ represent reflectance, absorbance, and transmittance coefficients, respectively. These can be described in terms of scattering parameters ( $S$-parameters), as obtained from testing, as follows:

$$
\begin{gathered}
T=\left|S_{12}\right|^{2}=\left|S_{21}\right|^{2} \\
R=\left|S_{11}\right|^{2}=\left|S_{22}\right|^{2} \\
A=1-R-T
\end{gathered}
$$

where $\left|S_{12}\right|^{2}\left(\left|S_{21}\right|^{2}\right)$ and $\left|S_{11}\right|^{2}\left(\left|S_{22}\right|^{2}\right)$ represent the power that is transmitted from port 1 to port 2 and vice versa, and the reflected power in both ports, respectively. The scattering parameters were obtained using the same set up described above for EMI SE measurements, but for these, only the load specimen was required.

\section{Results}

3.1. Morphological Analysis of Nonwoven Fiber Mats, MWCNT-Carbon Nanofiber Composite Mats, and Interlayered Composites

The microstructural analysis and fiber diameter distributions of spun nanofibers from solutions containing $10 \mathrm{wt}$.\% PVA without the addition of MWCNT and the corresponding CNF mat obtained after the dehydration and carbonization processes are illustrated in Figure 3. Figure 3a depicts the spun PVA nanofibers, showing long continuous nanofibers with homogeneous surfaces and diameters that are mostly within the 400-600 nm range (Figure 3c). Figure 3b shows the developed carbon nanofibers after exposure to dehydration by the sulfuric acid vapor and subsequent heat treatment. The average carbon fiber diameter after heat treatment was $580 \mathrm{~nm}$.
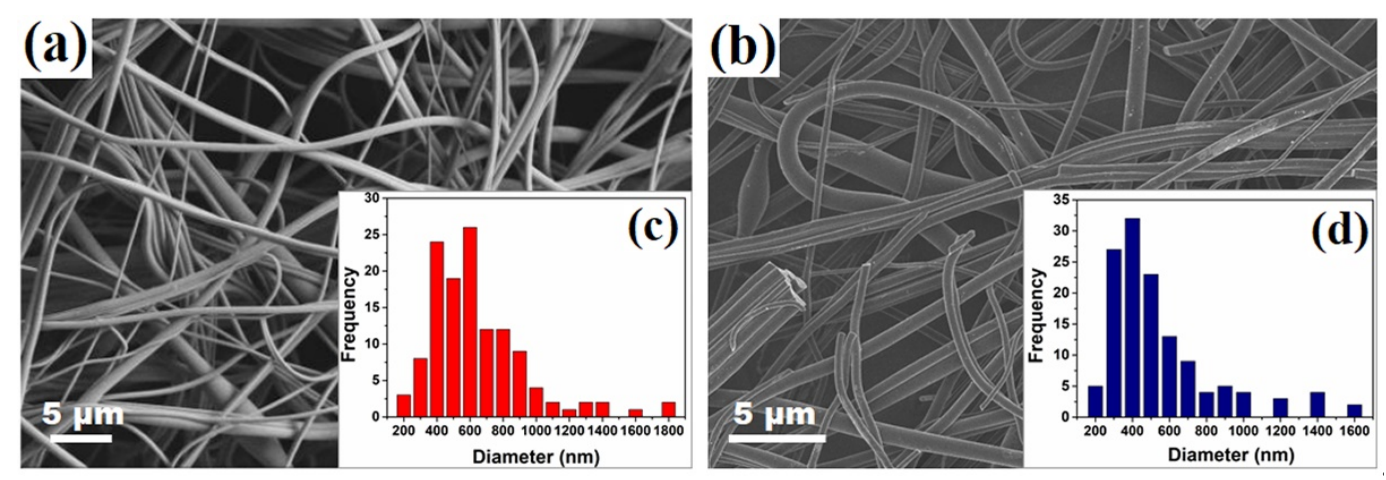

Figure 3. SEM images of (a) nonwoven Poly(vinyl alcohol) (PVA) nanofibers mat and (b) nonwoven carbon nanofibers (CNF) mat without MWCNT. Histograms representing fiber diameter distributions are shown as insets for both systems (c) and (d).

Figure 4 shows a comparison of the SEM images of the MWCNT filled carbon nanofiber mats with different MWCNT contents, before and after the carbonization process. It can be observed that the surface structure of the hybrid nonwoven nanofibers before the carbonization process appear to 
be homogeneous, with surfaces free of defects (Figure $4 a, c)$. After the heat treatment, the surface of the fibers is significantly altered, as seen in Figure $4 \mathrm{~b}$,d. It is clearly observed that the nanofibers exhibit a rougher surface when compared to the pure PVA nanofibers and carbonized PVA fibers; and, the addition of the MWCNT resulted in a heterogeneous surface upon carbonization. Voids are clearly observed in the carbon nanofibers, which became more notable as the MWCNT content was augmented. During the initial formation of the fibers, solvent that is trapped in between MWCNT does not completely evaporates, upon carbonization, solvent or even not carbonized polymer leaves the system, leaving behind a porous surface.
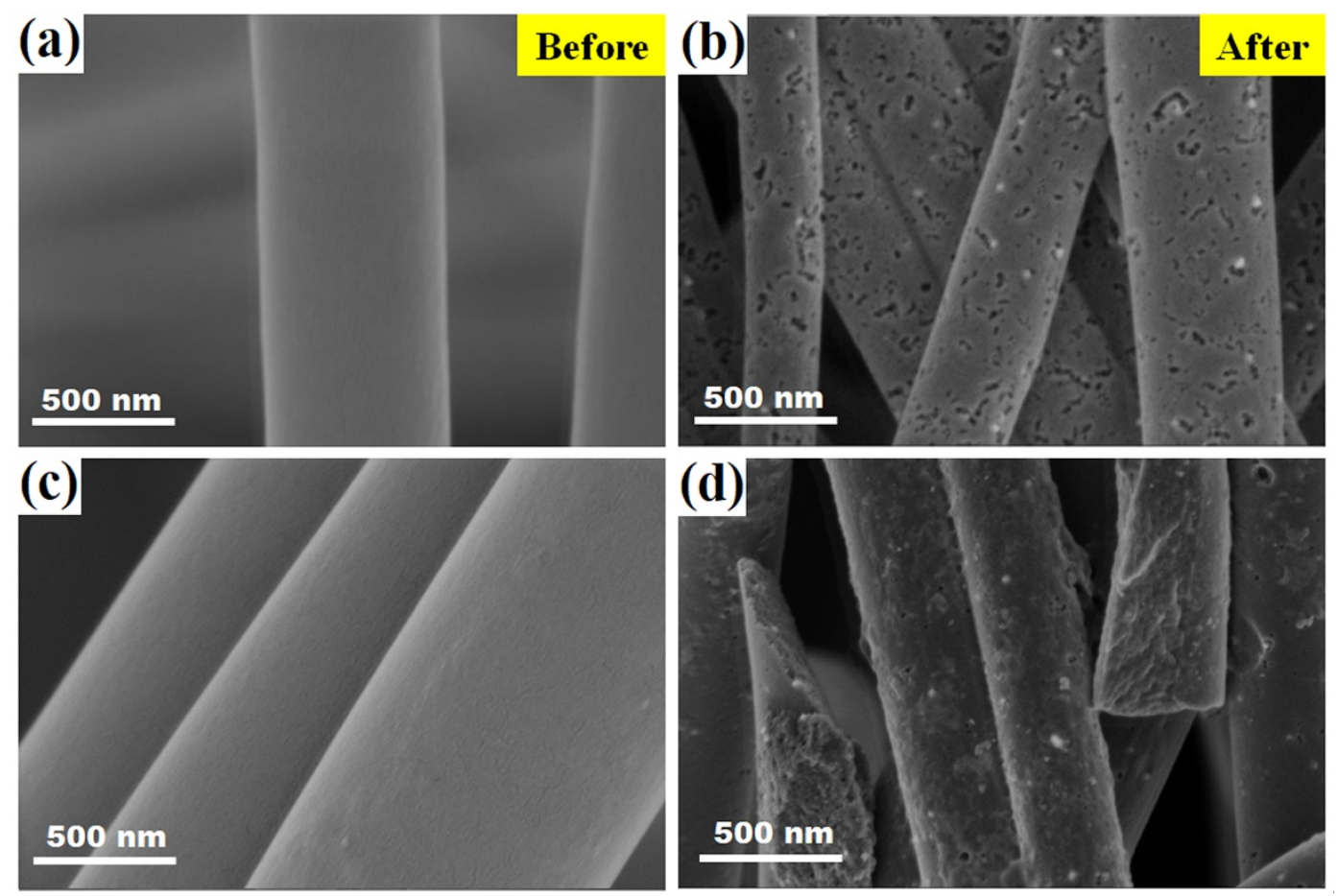

Figure 4. SEM images of MWCNT filled carbon nanofiber mats with different contents of MWCNT before and after carbonization. (a,c) PVA nanofibers mats with 0.05 and 0.1 wt.\% MWCNT and $(\mathbf{b}, \mathbf{d})$ CNF mats filled with 0.05 and 0.1 wt.\% MWCNT, respectively.

SEM micrographs of some of the developed polymer composites are shown in Figure 5. As observed, the NRPCS that was prepared from PP and MWCNT exhibits a homogeneous distribution of MWCNT, lacking large agglomerates (Figure 5a). This helps in promoting the formation of a conductive network that is needed for percolation. In the same way, when the hybrid nonwoven CNF mats were embedded with the NRPCS (Figure 5b), it is clear that the polymer resin wets the developed CNF mats. Figure $5 c$ shows the cross-sectional area of an eight-layer composite. This sample is composed of eight MWCNT filled carbon nanofiber mats pressed in between layers of NRPCS. The MWCNT filled carbon nanofiber mats can be distinguished by observing the darker areas running almost parallel to one another; these layers appear intercalated among the layers of NRPCS. 

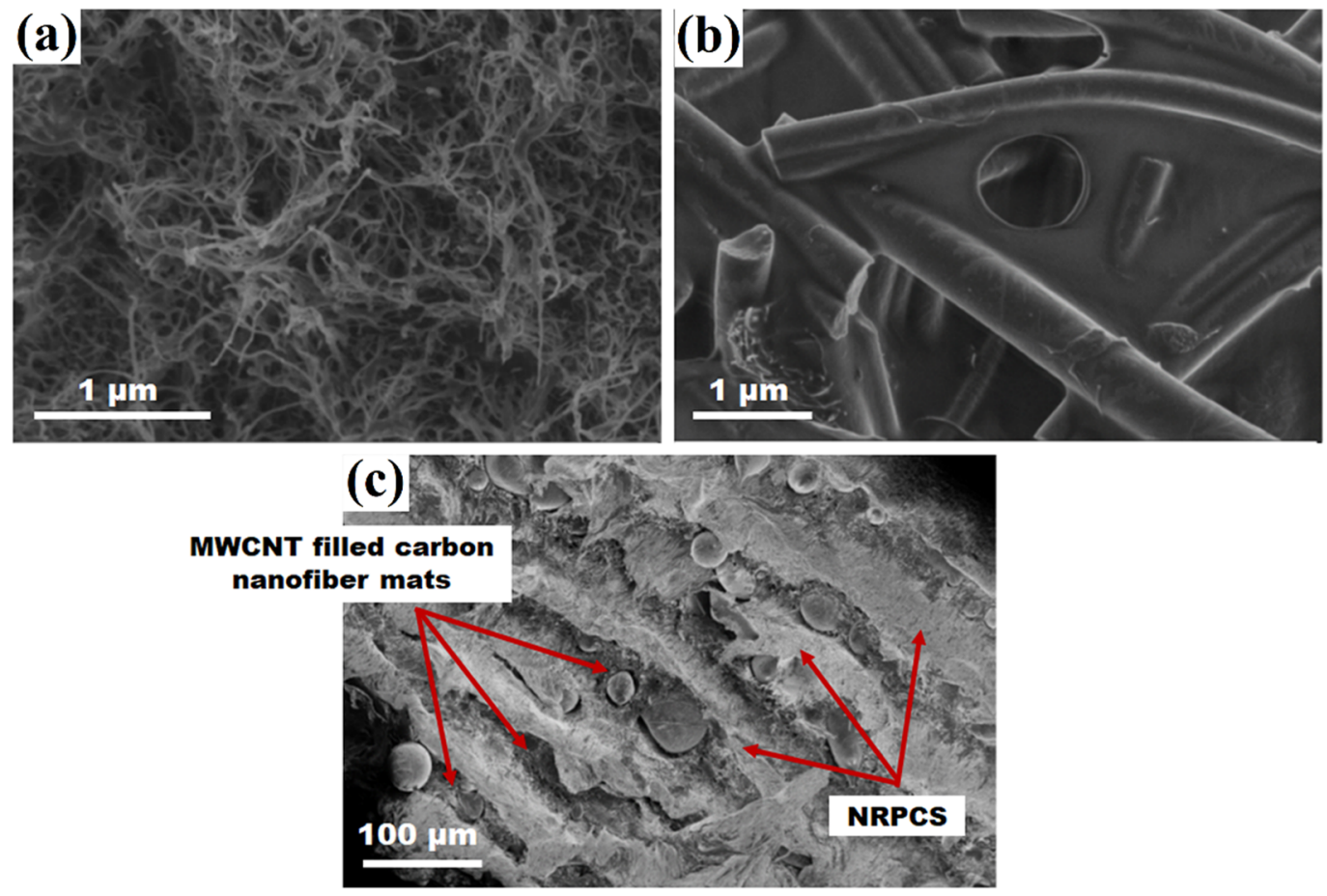

Figure 5. SEM images of (a) a cross-sectional of the NRPCS; (b) MWCNT filled carbon nanofiber mat embedded within the NRPCS; and, (c) the cross-sectional area of an eight-layered flexible composite.

\subsection{Electrical Properties of MWCNT Filled Carbon Nanofiber Mat and Interlayered Composites}

The in-plane electrical conductivity of MWCNT filled carbon nanofiber mats and interlayered composites were analyzed. Table 2 shows the effect of the addition of MWCNT to CNF. As it can be observed, the CNF mat without MWCNT exhibited a value of electrical conductivity of $\sim 1 \mathrm{~S} \cdot \mathrm{cm}^{-1}$, while the addition of $0.1 \mathrm{wt} . \%$ of MWCNT led to a slight increase of the in-plane electrical conductivity to $2.8 \mathrm{~S} \cdot \mathrm{cm}^{-1}(0.36 \Omega \cdot \mathrm{cm}$ in electrical resistivity). The in-plane electrical conductivity of the NRPCS and the composite in the one layer of nonwoven CNF mats containing $0,0.05$, or $0.1 \mathrm{wt} . \%$ of MWCNT shows continuous increments as the MWCNT content is increased. The interlayered composite containing one layer of CNF mat filled with $0.1 \mathrm{wt} . \%$ of MWCNT shows a value that is three times higher $\left(4.5 \mathrm{~S} \cdot \mathrm{cm}^{-1}\right)$ than the reference sheet (NRPCS) and a factor of 1.5 higher than the composite using the CNF mat without MWCNT.

Table 2. Values of in-plane and through-plane electrical resistivity/conductivity of produced composites.

\begin{tabular}{|c|c|c|c|c|c|}
\hline ID Sample & $\begin{array}{l}\text { Thickness } \\
\text { (mm) }\end{array}$ & $\begin{array}{c}\text { In-Plane } \\
\text { Resistivity, } \rho_{i} \\
(\Omega \cdot \mathrm{cm})\end{array}$ & $\begin{array}{c}\text { In-Plane } \\
\text { Conductivity, } \sigma_{i} \\
\left(\mathrm{~S} \cdot \mathrm{cm}^{-1}\right)\end{array}$ & $\begin{array}{c}\text { Through-Plane } \\
\text { Resistivity, } \rho_{t} \\
(\Omega \cdot \mathrm{cm})\end{array}$ & $\begin{array}{l}\text { Through-Plane } \\
\text { Conductivity, } \sigma_{t} \\
\left(\mathrm{~S} \cdot \mathrm{cm}^{-1}\right)\end{array}$ \\
\hline CNF mat & 0.11 & $0.89 \pm 0.07$ & $1.1 \pm 0.1$ & 423 & $2.4 \times 10^{-3}$ \\
\hline CNF-0.05MWCNT & 0.09 & $0.38 \pm 0.02$ & $2.6 \pm 0.1$ & - & - \\
\hline CNF-0.1MWCNT & 0.09 & $0.36 \pm 0.01$ & $2.8 \pm 0.1$ & 337 & $3.0 \times 10^{-3}$ \\
\hline NRPCS & 0.13 & $0.67 \pm 0.05$ & $1.5 \pm 0.1$ & 93 & $1.1 \times 10^{-2}$ \\
\hline IC-1-0 & 0.10 & $0.35 \pm 0.05$ & $2.8 \pm 0.5$ & - & - \\
\hline IC-1-0.05 & 0.10 & $0.26 \pm 0.02$ & $3.8 \pm 0.2$ & - & - \\
\hline IC-1-0.1 & 0.10 & $0.23 \pm 0.02$ & $4.5 \pm 0.3$ & 232 & $4.3 \times 10^{-3}$ \\
\hline IC-2-0.1 & 0.16 & $0.20 \pm 0.02$ & $4.9 \pm 0.4$ & 104 & $9.6 \times 10^{-3}$ \\
\hline IC-4-0.1 & 0.30 & $0.19 \pm 0.06$ & $5.3 \pm 1.5$ & 70 & $1.4 \times 10^{-2}$ \\
\hline IC-8-0.1 & 0.65 & $0.16 \pm 0.03$ & $6.1 \pm 1.1$ & 34 & $3.0 \times 10^{-2}$ \\
\hline
\end{tabular}

Adding more layers and increasing the content of MWCNT within the carbon nanofiber mat increases the electrical conductivity. The in-plane electrical conductivity of the composite with $0.1 \mathrm{wt} . \%$ of MWCNT within the carbon nanofiber mats increased from 4.5 up to $6.1 \mathrm{~S} \cdot \mathrm{cm}^{-1}(0.23$ to 
$0.16 \Omega \cdot \mathrm{cm}$ in electrical resistivity) for the interlayered composite containing eight layers. The increase in electrical conductivity of the multilayered systems is not significantly depicted in the in-plane conductivity measurements. Through-plane conductivity analysis, additional information that is especially related to these interlayered composites is provided. As the layers of MWCNT-carbon nanofiber composite mats and NRPCS increase, the through-plane conductivity increases, as depicted in Table 2, which summarizes the surface and volume electrical conductivity. It is clearly noted that, in all cases, the volume electrical conductivity is lower than the corresponding surface conductivity by at least by two orders of magnitude. The maximum value of volume electrical conductivity reached $3 \times 10^{-2} \mathrm{~S} \mathrm{~cm}^{-1}$ in the eight-layered flexible composite.

\subsection{EMI Shielding Effectiveness}

According to the literature, the obtained electrical conductivity values are considered low to satisfy EMI shielding related applications [35-37]; though, electrical conductivity is not the absolute criterion to shield EMI $[4,38]$. EMI is attenuated by three major mechanisms: reflection, absorption, and multiple reflections. For reflection of the radiation from the surface of the shield, the shield must have mobile charge carriers to interact with the incoming electromagnetic field. Consequently, the shielding material tends to be electrically conductive [4,30,31,36,39]. Absorption is related to the existence of electric and/or magnetic dipoles in the shielding material, which interacts with the electromagnetic field. Multiple reflections refer to the reflections at various surfaces or interfaces within the shield, which are typically observed in systems that are loaded with fillers of large surface area, and therefore high interfacial area within the overall structure $[4,32,36]$. When the shielding by absorption is higher than $10 \mathrm{~dB}$ or when the distance between the reflecting surfaces or interfaces is large when compared to the skin depth, multiple reflections can be ignored, as it is often observed in metallic systems $[4,31,33,36]$.

The total experimental EMI SE versus frequency of the developed samples is shown in Figure 6a. The nonwoven CNF mat displays an SE value of $\sim 12 \mathrm{~dB}$, upon the addition of MWCNT $(0.05$ and 0.1 wt.\%), a slight increase is obtained, reaching a value of $14 \mathrm{~dB}$. The nanoreinforced polymer composite shows similar SE values. The combination of one layer of nonwoven MWCNT filled carbon nanofiber mat with NRPCS shows a slight increase to $17 \mathrm{~dB}$ (thickness of $0.10 \mathrm{~mm}$ ) at $900 \mathrm{MHz}$ (Figure 6a). Upon the addition of more layers, the SE increased considerably (Figure 6b). A two-layer composite (IC-2-0.1) almost doubled its SE, to $31 \mathrm{~dB}$. The eight-layered flexible sample composed of nonwoven 0.1 wt.\% MWCNT filled carbon nanofiber mats (IC-8-0.1) shows an ability to shield $>50 \mathrm{~dB}$ at the tested frequencies within the $S$-band region.
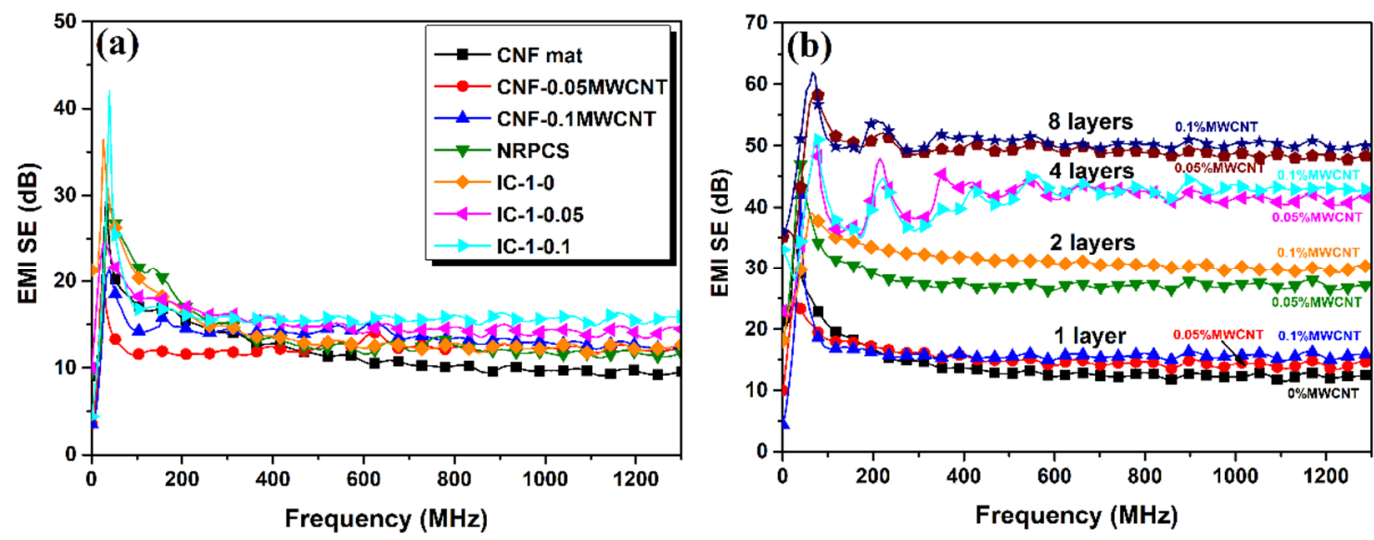

Figure 6. (a) Total experimental EMI shielding effectiveness (EMI SE) of nonwoven CNF mat, NRPCS, MWCNT filled carbon nanofiber mats with different MWCNT contents, and one-layered flexible composites; and (b) EMI SE of interlayered composites formed by different number of layers of MWCNT filled carbon nanofiber mats with variable MWCNT concentration. 
On the other hand, for lightweight shielding materials, the specific SE (SSE, in $\left.\mathrm{dB} \cdot \mathrm{cm}^{3} \cdot \mathrm{g}^{-1}\right)$, defined as SE divided by density (in $\mathrm{g} \cdot \mathrm{cm}^{-3}$ ), is also a critical parameter $[40,41]$. SSE provides accurate EMI SE information by considering the density, $\rho$, of the material (see Table 1), where a thinner material or one with lower density might exhibit higher EMI SE [41-43]. When considering that the SSE does not give thickness-based information, the absolute shielding effectiveness (SSE/ $t$ in $\left.\mathrm{dB} \cdot \mathrm{cm}^{2} \cdot \mathrm{g}^{-1}\right)$ is used to evaluate the relationship between SSE and thickness. Table 3 shows the values of EMI SE, SSE, and SSE/ $t$ of each produced composite. In the S-band region, the nonwoven CNF mat without the incorporation of MWCNT shows a value of SSE of $36.1 \mathrm{~dB} \cdot \mathrm{cm}^{3} \cdot \mathrm{g}^{-1}$, which is increased to $48.9 \mathrm{~dB} \cdot \mathrm{cm}^{3} \cdot \mathrm{g}^{-1}$ with the addition of $0.1 \mathrm{wt} . \%$ of MWCNT. In the interlayered composites containing one and two layers of CNF mats, a significant decrease of the SSE was recorded, and then the values of SSE were augmented as the number of layers increased. A maximum value of SSE of $76.5 \mathrm{~dB} \cdot \mathrm{cm}^{3} \cdot \mathrm{g}^{-1}$ was obtained for the IC-8-0.1 composite, which displayed the lowest density of the interlayered composites that were produced in this work $\left(0.68 \mathrm{~g} \cdot \mathrm{cm}^{-3}\right)$. Similarly, the SSE/ $t$ values show increases with the addition of MWCNT to the CNF mats, reaching a maximum value of $5433.3 \mathrm{~dB} \cdot \mathrm{cm}^{2} \cdot \mathrm{g}^{-1}$. The interlayered composites exhibit lower values than those of the CNF mats. These values were highly increased in the two-layered composite. The increase in the thickness of the interlayered samples from 0.3 to $0.65 \mathrm{~mm}$ in IC-4-0.1 and IC-8-0.1 composites caused a remarkable decrease in the SSE/ $t$ values, recording a minimum value of $1176.9 \mathrm{~dB} \cdot \mathrm{cm}^{2} \cdot \mathrm{g}^{-1}$ in the IC-8-0.1 composite. It can be noted that the increase in the thickness of these samples is mainly due to the presence of a significant amount of NRPCS in the interlayered structures. As it is well known, the PP matrix that is used to fabricate the NRPCS is transparent to the electromagnetic interference, exhibiting values of attenuation close to $0 \mathrm{~dB}[42,44]$, prompting the decrease in the SSE/ $t$ values in these composites.

Table 3. Values of average EMI SE, specific SE (SSE), and absolute shielding effectiveness (SSE/t) of produced composites.

\begin{tabular}{cccc}
\hline ID Sample & Average EMI SE (dB) & SSE $\left(\mathbf{d B} \cdot \mathbf{c m}^{\mathbf{3}} \cdot \mathbf{g}^{\mathbf{- 1}}\right)$ & SSE $/ \boldsymbol{t}\left(\mathbf{d B} \cdot \mathbf{c m}^{\mathbf{2}} \cdot \mathbf{g}^{-\mathbf{1}}\right)$ \\
\hline CNF mat & 11.9 & 36.1 & 3281.8 \\
CNF-0.05MWCNT & 12.2 & 40.7 & 4522.2 \\
CNF-0.1MWCNT & 13.7 & 48.9 & 5433.3 \\
NRPCS & 13.9 & 14.1 & 1084.6 \\
IC-1-0 & 14.3 & 18.1 & 1810.0 \\
IC-1-0.05 & 15.4 & 19.5 & 1950.0 \\
IC-1-0.1 & 16.9 & 21.7 & 2170.0 \\
IC-2-0.1 & 31.1 & 42.6 & 2662.5 \\
IC-4-0.1 & 41.5 & 59.3 & 1976.7 \\
IC-8-0.1 & 52.0 & 76.5 & 1176.9 \\
\hline
\end{tabular}

The reflectance $(R)$, transmittance $(T)$, and absorbance $(A)$ power coefficients for selected samples (IC-1-0.1, IC-4-0.1, and IC-8-0.1) are shown in Figure 7. Interlayered composites display a significant increase in the $R$ coefficient when the frequency was increased to about $300 \mathrm{MHz}$. In turn, the $A$ coefficient showed an inverse behavior to $R$, diminishing at lower frequencies, followed by slight increase (Figure 7). As observed, a higher reflection coefficient and a lower absorption coefficient was recorded as the number of layers of nonwoven $0.1 \mathrm{wt} . \%$ MWCNT filled carbon nanofiber mats increased. According to Equations (4)-(6), the shielding by reflection ( $S E_{\text {ref }}$ ) or reflection loss, the shielding by absorption $\left(S E_{\mathrm{abs}}\right)$ or absorption loss, and the total $S E$ ( $\left.S E_{\mathrm{Total}}\right)$ of the composites that are mentioned above were calculated and plotted vs. frequency (Figure 8). In the $0-300 \mathrm{MHz}$ frequency range, $S E_{\text {abs }}$ decreases while $S E_{\text {ref }}$ augments. Above $600 \mathrm{MHz}$, both $S E_{\text {abs }}$ and $S E_{\text {ref }}$ exhibit a constant trend as frequency increases up to $1300 \mathrm{MHz}$. All of the samples show $S E_{\mathrm{abs}}$ higher than $S E_{\text {ref. }} S E_{\text {abs }}$ represents 75,82 , and $81 \%$ of the overall shielding for the IC-1-0.1, IC-4-0.1, and IC-8-0.1 composites, respectively. Also, it is clearly observed that $S E_{\text {abs }}$ increases as the number of layers increased from 1 to 4 ; however, 
in the IC-8-0.1 composite, this trend was not observed, showing almost the same absorption loss than the IC-4-0.1 composite.
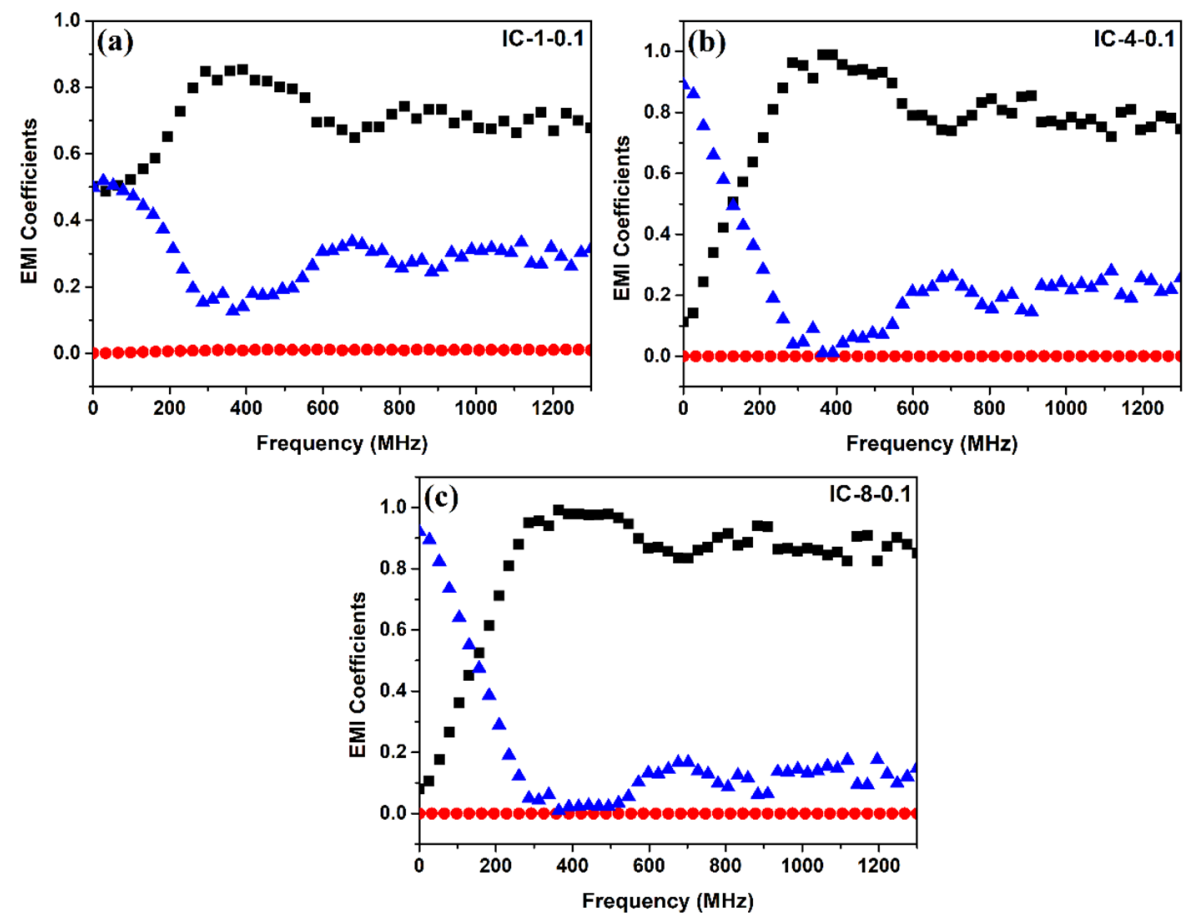

Figure 7. EMI power coefficients of reflectance $(\square)$, transmittance $(\boldsymbol{)})$, and absorbance $(\boldsymbol{\Delta})$ of the interlayered composites: (a) IC-1-0.1; (b) IC-4-0.1; and, (c) IC-8-0.1.
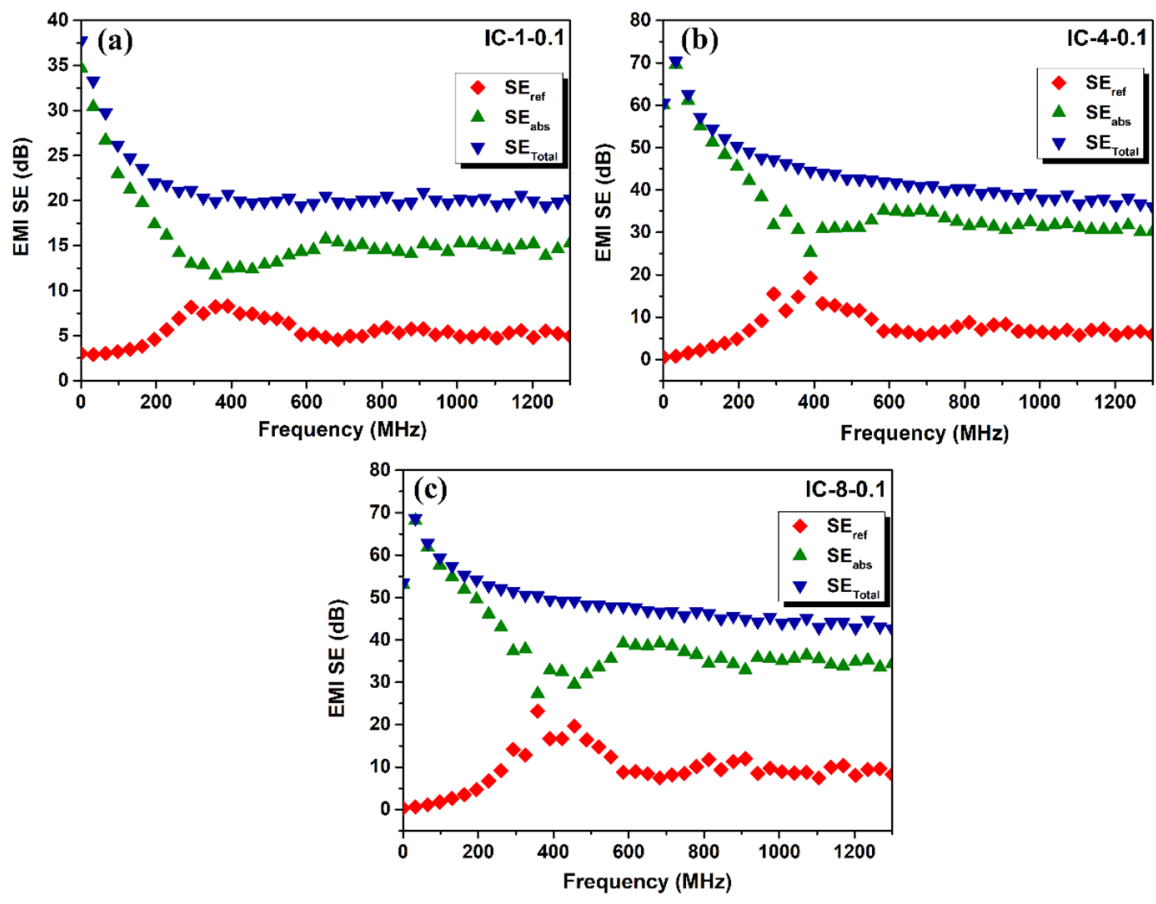

Figure 8. Reflection, $S E_{\text {ref }}(\diamond)$, absorption, $S E_{\text {abs }}(\boldsymbol{\Delta})$, and total $S E, S E_{\text {Total }}(\boldsymbol{\nabla})$ for interlayered composites: (a) IC-1-0.1; (b) IC-4-0.1; and, (c) IC-8-0.1. 
Theoretical analysis of the EMI SE was carried out to evaluate the individual contributions of absorption and reflection according to [30,32-34,45]:

$$
\begin{gathered}
S E_{A}=8.7 \frac{t}{\delta}=8.7 t \sqrt{\pi f \mu \sigma} \\
S E_{R}=20 \log \left(\frac{\sqrt{\mu_{0} \sigma}}{4 \sqrt{2 \pi f \mu \varepsilon_{0}}}\right)
\end{gathered}
$$

where $t$ is the thickness of the sample, $f$ is the frequency, $\mu$ is the magnetic permeability $=\mu_{0} \mu_{\mathrm{r}}\left(\mu_{0}=4 \pi\right.$ $\left.\times 10^{-7} \mathrm{H} \cdot \mathrm{m}^{-1}, \mu_{\mathrm{r}}=1\right), \sigma$ is the bulk electrical conductivity in $\Omega^{-1} \cdot \mathrm{m}^{-1}$, and $\varepsilon_{0}=8.854 \times 10^{-12} \mathrm{~F} \cdot \mathrm{m}^{-1}$.

Figure $9 \mathrm{a}-\mathrm{c}$ shows the calculated EMI SE by absorption $\left(S E_{\mathrm{A}}\right)$, reflection $\left(S E_{\mathrm{R}}\right)$, and the total $\mathrm{SE}\left(S E_{\mathrm{T}}\right)$ of some representative samples. As observed, $S E_{\mathrm{A}}$ increases as frequency increases. In the interlayered composites, it is clearly observed that, as the number of layers (or the thickness) is increased, the SE by absorption augments (Figure 9a). This behavior is due to the larger presence of effective material, which sustains the fact that materials with higher thickness (at the scale of $\mathrm{mm}$ ) exhibit significant absorption attenuation in EMI shielding [4,32]. On the other hand, the $S E_{\mathrm{R}}$ or reflection loss plotted in Figure $9 \mathrm{~b}$ shows an inverse behavior to $S E_{\mathrm{A}}$, decreasing their value as the frequency increases. Interlayered composites display a higher reflection loss as the number of layers increase. Furthermore, it was found that the contribution of $S E_{\mathrm{R}}$ to the total shielding (Figure 9c) was notably higher than the contribution of $S E_{\mathrm{A}}$ in all the samples.
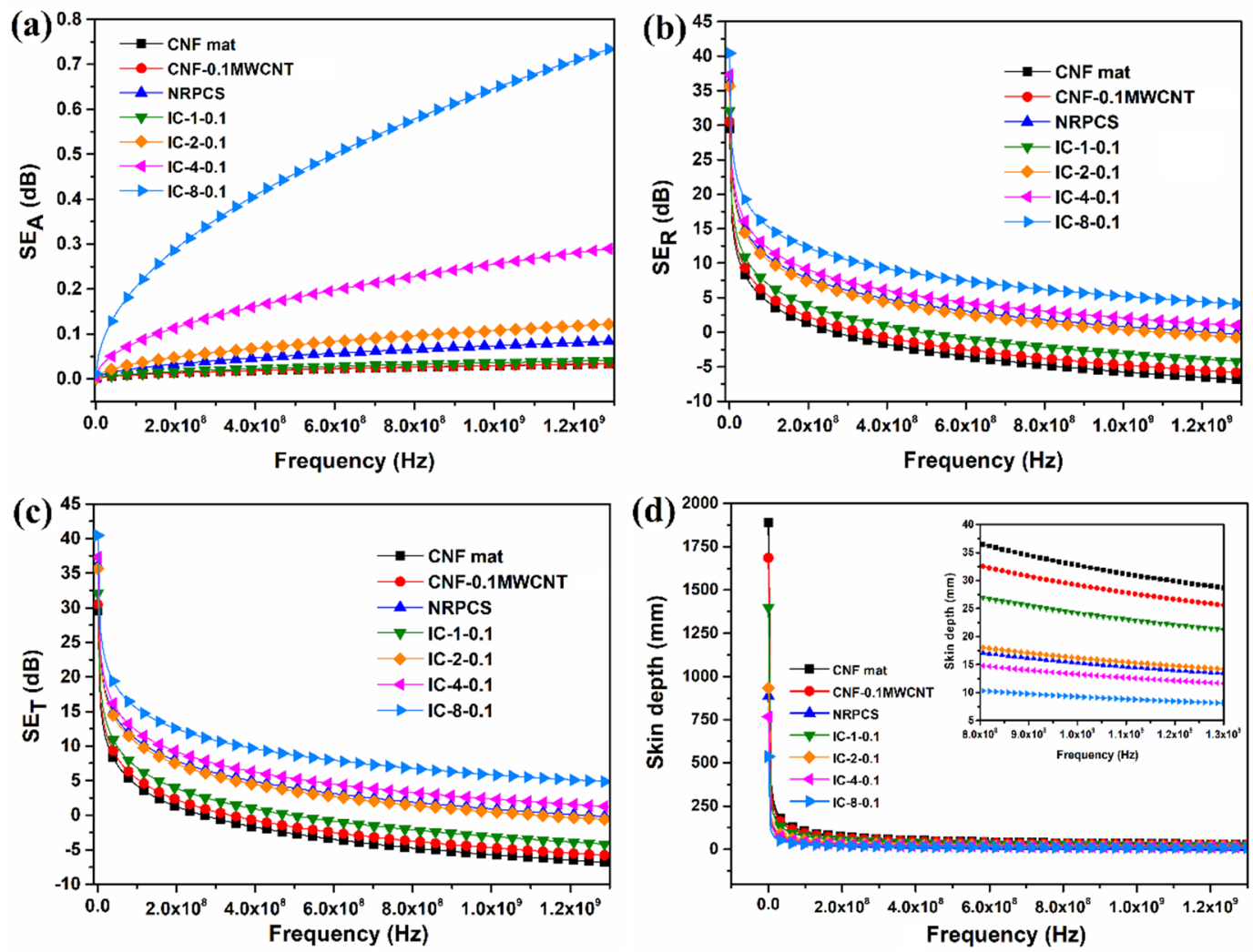

Figure 9. Calculated EMI SE versus frequency. (a) $S E_{\mathrm{A}}$; (b) $S E_{\mathrm{R}}$; (c) $S E_{\mathrm{T}}$ of CNF mat, 0.1 wt.\% MWCNT filled carbon nanofiber mat, NRPCS and interlayered composites formed by different number of layers of 0.1 wt.\% MWCNT filled carbon nanofiber mats; and, (d) Skin depth dependence with respect to frequency. The inset in (d) shows a zooming view of skin depth at higher frequencies $(0.8-1.3 \mathrm{GHz})$.

Besides, Figure 9a shows that, even though the absorption component increases with increasing the number of layers and the frequency, the contribution was almost negligible when compared to the 
reflection component (Figure $9 \mathrm{~b}$ ). Furthermore, the theoretical $S E_{\mathrm{T}}$ differed from the values that were obtained experimentally, for example, for the eight-layered system, the $S E_{\mathrm{T}}$ is calculated to be $\sim 10 \mathrm{~dB}$ (Figure 9c) when it experimentally is $52 \mathrm{~dB}$, as shown in Figure $6 \mathrm{~b}$ and Table 3. These results reflect that, in this type of systems, the multiple reflection contribution seems significant. Since multiple reflections depend on the thickness relationship between skin depth and distance from reflection to interface; the skin depth of the samples was obtained from Equation (12) [4,36]:

$$
\delta=\frac{1}{\sqrt{\pi f \mu \sigma}}
$$

As shown in Figure 9d, the skin depth of all samples diminished when the frequency was increased. In the inset, it is clearly observed that, in the materials with lower electrical conductivity and thickness, the skin depth recorded higher values; whereas, in the interlayered composites, the increase in the number of layers, the thickness, and the electrical conductivity led to notable decreases in skin depth.

\section{Discussion}

As observed, the presence of low percentages of MWCNT enhances electrical conduction along the carbon nanofiber network. Similar observations have also been reported in previous studies related to MWCNT reinforced carbon nanofibers used in hybrid or multiscale structures $[15,38,46-48]$. The infiltration process of the CNF mat by the polymer composite allowed the formation of interconnected areas and continuous paths that led to synergistic effects on the electrical properties of the interlayered composite. Given the two-dimensional (2D) structure of the nanofiber mats, there is a preferential conduction path in the in-plane direction, which does not favor the electron transport in the through-plane direction. Similar findings have been documented in previous studies of layered composites, showing decreases from one to four orders of magnitude with respect to the in-plane measurements $[19,20]$. The lower values that were observed in the through-plane conductivity measurements are also due to the higher number of interfaces. It is also found that the in-plane conductivity, even though increases upon the addition of layers, the effect is minimal when compared to the effect of the number of layers on the through-plane conductivity, which increases at least one order of magnitude upon the addition of more layers.

The incorporation of MWCNT (0.05 and $0.1 \mathrm{wt} . \%)$ to the nonwoven CNF mats, as well as the increase in the number of layers of the interlayered composites, led to an enhancement of EMI shielding performance. Literature shows a broad number of studies that focus on the development of flexible, lightweight high-efficiency EMI shielding composites in a variety of structures (foams, solid/films or stacked/laminated materials). Table 4 summarizes some shielding effectiveness values previously reported and, for comparison, the results of the present work on similar materials are included. As a first observation, carbon-based fillers are mostly preferred to increased EMI SE performance due to their large aspect ratio and low density when compared to metal fillers. EMI SE is mostly proportional to the thickness of the samples. However, in the studies of Chang et al. [49], Raagulan et al. [43], Jou et al. [50], and Lee at al. [34], high values of EMI SE (34, 54, 60, and 133 dB, respectively) in materials, like films and foams, with relatively low thicknesses (from 0.15 to $0.6 \mathrm{~mm}$ ) were found. In our case, the value of $52 \mathrm{~dB}$ obtained for the IC-8-0.1 composite is quite promising and comparable to those that were reported by these authors when considering that the thickness $(0.65 \mathrm{~mm})$ and amount of filler used in this interlayered composite is lower than the reported by Chang et al. [49] and Jou et al. [50].

A maximum value of $1148 \mathrm{~dB} \cdot \mathrm{cm}^{3} \cdot \mathrm{g}^{-1}$ has been reported by Zeng et al. [41] in anisotropic porous water-borne polyurethane (WPU)-MWCNT composites assembled by the freeze-drying method. These structures exhibit low density $\left(0.126 \mathrm{~g} \cdot \mathrm{cm}^{-3}\right)$. On the other hand, it is observed that a value of $76.5 \mathrm{~dB} \cdot \mathrm{cm}^{3} \cdot \mathrm{g}^{-1}$ was obtained for the interlayered composite that was developed in the current work, which surpasses the values that were obtained in various porous structures with similar thicknesses 
$(<1 \mathrm{~mm})$, as listed in Table 4 . This value demonstrates that the IC-8-0.1 composite is sufficiently a lightweight system that exhibits an adequate EMI shielding performance and it can be produced through a facile, cost-effective, and scalable method when compared to other systems.

When considering the values of absolute SE (SEE/t), the CNF-MWCNT mat containing $0.1 \mathrm{wt} . \%$ of MWCNT, developed in this work, exhibited a value of $5433.3 \mathrm{~dB} \cdot \mathrm{cm}^{2} \cdot \mathrm{g}^{-1}$, which is higher than those of flexible graphite $\left(606 \mathrm{~dB} \cdot \mathrm{cm}^{2} \cdot \mathrm{g}^{-1}\right)$ [51] and graphene foams (5000 and $\left.1324 \mathrm{~dB} \cdot \mathrm{cm}^{2} \cdot \mathrm{g}^{-1}\right)[40,43]$. In turn, the eight-layered composite showed a value of SSE/ $t$ slightly lower than those that were reported by Raagulan et al. [43] for MGNC-PVDF foams (1324 and $1944 \mathrm{~dB} \cdot \mathrm{cm}^{2} \cdot \mathrm{g}^{-1}$ in the $S$-band and $X$-band region, respectively) whose thicknesses are similar to our composites.

Table 4. Comparison of reported values of EMI SE, SSE, and SSE/ $t$ for different composites and the developed materials in this work.

\begin{tabular}{|c|c|c|c|c|c|c|c|}
\hline Material & $\begin{array}{c}\text { Filler } \\
\text { Content }\end{array}$ & $t(\mathrm{~mm})$ & $\begin{array}{l}\text { EMI SE } \\
\text { (dB) }\end{array}$ & $\begin{array}{c}\text { SSE } \\
\left(\mathrm{dB} \cdot \mathrm{cm}^{3} \cdot \mathrm{g}^{-1}\right)\end{array}$ & $\begin{array}{c}\mathrm{SSE} / t \\
\left(\mathrm{~dB} \cdot \mathrm{cm}^{2} \cdot \mathrm{g}^{-1}\right)\end{array}$ & $\begin{array}{c}\text { Frequency } \\
\text { Range (GHz) }\end{array}$ & Ref. \\
\hline Flexible graphite (Grafoil) & $\mathrm{N} / \mathrm{A}^{1}$ & 3.1 & 130 & 118 & 606 & $1-2$ & {$[51]$} \\
\hline $\begin{array}{l}\text { Carbon-carbon matrix } \\
\text { composite + CCF }\end{array}$ & $\mathrm{N} / \mathrm{A}$ & 2.4 & 124 & N/A & $\mathrm{N} / \mathrm{A}$ & $0.0003-1.5$ & [52] \\
\hline EVA-SCF ${ }^{2}$ sheets & $30 \mathrm{phr}$ & $1.8-3.5$ & $\begin{array}{l}25 \\
34\end{array}$ & $\mathrm{~N} / \mathrm{A}$ & $\mathrm{N} / \mathrm{A}$ & $\begin{array}{l}0.1-2 \\
8-12\end{array}$ & [53] \\
\hline $\mathrm{LCP}^{3}$-CNF composites & 15 wt. $\%$ & 1.45 & $\sim 41$ & $\mathrm{~N} / \mathrm{A}$ & $\mathrm{N} / \mathrm{A}$ & $0.015-1.5$ & [54] \\
\hline LCP-CNT composites & 50 wt. $\%$ & 1 & $\sim 60$ & $\mathrm{~N} / \mathrm{A}$ & $\mathrm{N} / \mathrm{A}$ & $0.3-1.8$ & {$[50]$} \\
\hline WPU -CF-CNT film & $\begin{array}{l}33 \text { wt. } \% \\
13 \text { wt. } \%\end{array}$ & 0.15 & 34 & $\mathrm{~N} / \mathrm{A}$ & $\mathrm{N} / \mathrm{A}$ & $0.05-1.5$ & [49] \\
\hline $\begin{array}{c}\text { Graphene-CNT- } \mathrm{Fe}_{2} \mathrm{O}_{3}+ \\
\text { PEDOT:PSS }{ }^{4} \text { film }\end{array}$ & $\mathrm{N} / \mathrm{A}$ & 0.6 & 133 & $\mathrm{~N} / \mathrm{A}$ & $\mathrm{N} / \mathrm{A}$ & $8-12$ & {$[34]$} \\
\hline PCL $^{5}$-MWCNT foam & 2 wt. $\%$ & 20 & $60-80$ & $193-258$ & $97-129$ & $0.04-40$ & [55] \\
\hline $\mathrm{MGNC}^{6}$ foam & $\operatorname{PVDF}^{7}$ & $\begin{array}{l}0.35 \\
0.35\end{array}$ & $\begin{array}{l}43 \\
54\end{array}$ & $\begin{array}{l}46 \\
68\end{array}$ & $\begin{array}{l}1324 \\
1944\end{array}$ & $\begin{array}{c}0-3 \\
8.2-12.4\end{array}$ & {$[43]$} \\
\hline PDMS $^{8}$-graphene foam & $0.8 w t . \%$ & 1 & 30 & 500 & 5000 & $8-12$ & {$[40]$} \\
\hline PP-SSF ${ }^{9}$ foam & 1.1 vol. $\%$ & 3.1 & 48 & 75 & 242 & $8-12.4$ & [42] \\
\hline WPU-MWCNT foam & 2.2 vol. $\%$ & 4.5 & 52 & 1148 & 2551 & $8.2-12.4$ & [41] \\
\hline PE-MWCNT BP laminates & $\mathrm{N} / \mathrm{A}$ & 1.5 & $\sim 100$ & $\mathrm{~N} / \mathrm{A}$ & $\mathrm{N} / \mathrm{A}$ & $2-18$ & [23] \\
\hline $\begin{array}{c}\text { PVA-MLG }{ }^{10} \text { sandwich } \\
\text { structure }\end{array}$ & $60 \mathrm{vol} . \%$ & $0.04-0.06$ & 14 & $\mathrm{~N} / \mathrm{A}$ & $\mathrm{N} / \mathrm{A}$ & $8.2-12.4$ & [32] \\
\hline PET-CF layered composite & $\mathrm{N} / \mathrm{A}$ & 1.98 & 60 & $\mathrm{~N} / \mathrm{A}$ & $\mathrm{N} / \mathrm{A}$ & $0.03-1.5$ & [25] \\
\hline $\begin{array}{l}\text { CNF-MWCNT mat IC-8-0.1 } \\
\text { interlayered composite }\end{array}$ & $\begin{array}{l}0.1 \text { wt. } \% \\
12 \text { wt. } \%\end{array}$ & $\begin{array}{l}0.09 \\
0.65\end{array}$ & $\begin{array}{c}13.7 \\
52\end{array}$ & $\begin{array}{l}48.9 \\
76.5\end{array}$ & $\begin{array}{l}5433.3 \\
1176.9\end{array}$ & $0.0003-1.3$ & This work \\
\hline
\end{tabular}

${ }^{1} \mathrm{~N} / \mathrm{A}$-value not reported or not available enough data to calculate it, ${ }^{2}$ EVA-SCF-Ethylene-vinyl acetate co-polymer-short carbon fiber, ${ }^{3}$ LCP-liquid crystal polymer, ${ }^{4}$ PEDOT:PSS-poly(3,4-ethylenedioxythiophene) poly(4-styrenesulfonate), ${ }_{5}$ PCL-polycaprolactone, 6 MGNC-Mxene-graphene composite, 7 PVDF-polyvinylidene fluoride, 8 PDMS-poly(dimethyl siloxane), 9 SSF-stainless steel fibers, ${ }^{10}$ MLG-multilayer graphene.

Based on the power coefficients and the shielding mechanisms that are shown in Figures 7 and 8 , it can be inferred that the developed interlayered composites possess high intrinsic absorption capabilities. However, when the electromagnetic waves strike the material, the reflection phenomena take place before absorption and most of the incident wave is reflected, as previously observed by Al-Saleh et al. [31] in ABS/CNT nanocomposites. According to earlier studies, when the distance between the reflecting surfaces or interfaces (shielding thickness) is larger when compared to the skin depth, the conductive materials would attenuate internal reflections, and thus, multiple reflections could be neglected $[4,32,36,39,56]$. Conversely, if the shielding thickness of the materials is smaller than the skin depth, multiple reflections would be considered in EMI shielding. Therefore, based on the results that were obtained, the calculated skin depth of all the samples is larger than the shielding thickness; so, multiple reflections are not to be ignored. When the thickness of the sample was smaller than the skin depth, low SE values were observed, however, when the number of layers increased, the skin depth becomes relatively smaller, therefore, increasing the overall shielding effectiveness. These results also show that the effect of multiple reflections is significant, given the high number of interfaces and the presence of fillers. 
In summary, the interlayered composites that were produced in this work represent a multifunctional system given its flexibility, lightweight, and high ability to attenuate electromagnetic waves; furthermore, when compared to other developed materials, the preparation of these composites is relatively simpler, which would facilitate their production at a large scale.

\section{Conclusions}

Carbon hybrid nanofiber mats and nanoreinforced polypropylene composites were developed and used to fabricate interlayered composites. The developed carbon fiber mats were prepared using an industrial scalable technique, Forcespinning ${ }^{\circledR}$, while the nanoreinforced polymer composite was prepared using a high shear mixer. The developed interlayered structures showed enhanced electrical conductivity and shielding of electromagnetic interference, in an eight-layer flexible composite that was composed of $18 \mathrm{wt} . \%$ (43 vol.\%) carbon content, $12 \mathrm{wt} . \%$ (9 vol.\%) MWCNT, and $70 \mathrm{wt} . \%$ (48 vol.\%) of $\mathrm{PP}$, the electrical conductivity was shown to be $6.1 \mathrm{~S} \cdot \mathrm{cm}^{-1}(0.16 \Omega \cdot \mathrm{cm}$ in electrical resistivity), while the shielding effectiveness was $52 \mathrm{~dB}$ for a $0.65 \mathrm{~mm}$ thick sample. When compared to previously reported studies, the development of this interlayered system provides a highly flexible material with an ability to tailor EMI shielding needs. The developed interlayered composites possess high intrinsic absorption capabilities. However, when the electromagnetic waves strike the material, the reflection phenomena take place before absorption, most of the incident wave is reflected and the rest travels through the system. This study opens up new opportunities for the fabrication of novel lightweight materials to be used in electronics; especially in those where communication systems, such as in airplanes or satellites, could be compromised due to the overcrowding of the spectral bands, the developed material could help to prevent the degradation of system performance.

Author Contributions: Conceptualization, C.A.R.-H., H.G. and K.L.; Formal analysis, C.A.R.-H., H.G. and L.B.; Funding acquisition, J.G.C.-M. and K.L.; Investigation, C.A.R.-H., H.G., F.d.l.T. and L.B.; Methodology, C.A.R.-H., H.G. and K.L.; Project administration, J.G.C.-M. and K.L.; Resources, J.G.C.-M. and K.L.; Supervision, J.G.C.-M. and K.L.; Validation, C.A.R.-H., H.G., F.d.l.T. and L.B.; Writing-original draft, C.A.R.-H.; Writing-review \& editing, C.A.R.-H., L.B. and K.L.

Funding: This research was funded by National Science Foundation under PREM grant DMR 1523577, and Consejo Nacional de Ciencia y Tecnología (CONACYT) by 221795-SEP CONACYT project. C.A.R.-H. is grateful to CONACYT for a graduate fellowship with registration number 394307.

Conflicts of Interest: The authors declare no conflict of interest.

\section{References}

1. Njuguna, J.; Pielichowski, K.; Fan, J. Polymer nanocomposites for aerospace applications. In Advances in Polymer Nanocomposites: Types and Applications, 1st ed.; Gao, F., Ed.; Woodhead Publishing Limited: Cambridge, UK, 2012; pp. 472-539.

2. Müller, K.; Bugnicourt, E.; Latorre, M.; Jorda, M.; Echegoyen Sanz, Y.; Lagaron, J.M.; Miesbauer, O.; Bianchin, A.; Hankin, S.; Bölz, U.; et al. Review on the processing and properties of polymer nanocomposites and nanocoatings and their applications in the packaging, automotive and solar energy fields. Nanomaterials 2017, 7, 74. [CrossRef] [PubMed]

3. Mittal, G.; Rhee, K.Y.; Mišković-Stanković, V.; Hui, D. Reinforcements in multi-scale polymer composites: Processing, properties, and applications. Compos. Part B 2017, 138, 122-139. [CrossRef]

4. Chung, D.D.L. Electromagnetic interference shielding effectiveness of carbon materials. Carbon 2001, 39, 279-285. [CrossRef]

5. Moniruzzaman, M.; Winey, K.I. Polymer nanocomposites containing carbon nanotubes. Macromolecules 2006, 39, 5194-5205. [CrossRef]

6. Spitalsky, Z.; Tasis, D.; Papagelis, K.; Galiotis, C. Carbon nanotube-polymer composites: chemistry, processing, mechanical and electrical properties. Prog. Polym. Sci. 2010, 35, 357-401. [CrossRef]

7. Mittal, G.; Dhand, V.; Rhee, K.Y.; Park, S.-J.; Lee, W.R. A review on carbon nanotubes and graphene as fillers in reinforced polymer nanocomposites. J. Ind. Eng. Chem. 2015, 21, 11-25. [CrossRef] 
8. Al-Saleh, M.H.; Sundararaj, U. A review of vapor grown carbon nanofiber/polymer conductive composites. Carbon 2009, 47, 2-22. [CrossRef]

9. Tibbetts, G.G.; Lake, M.L.; Strong, K.L.; Rice, B.P. A review of the fabrication and properties of vapor-grown carbon nanofiber/polymer composites. Compos. Sci. Technol. 2007, 67, 1709-1718. [CrossRef]

10. Das, T.K.; Prusty, S. Graphene-based polymer composites and their applications. Polym. Plast. Technol. Eng. 2013, 52, 319-331. [CrossRef]

11. Papageorgiou, D.G.; Kinloch, I.A.; Young, R.J. Mechanical properties of graphene and graphene-based nanocomposites. Prog. Mater. Sci. 2017, 90, 75-127. [CrossRef]

12. Pandey, G.; Thostenson, E.T. Carbon nanotube-based multifunctional polymer nanocomposites. Polym. Rev. 2012, 52, 355-416. [CrossRef]

13. Lake, C.L.; Lake, P.D. Carbon nanofiber multifunctional mat. In Nanotube Superfiber Materials-Changing Engineering Design, 1st ed.; Schulz, M.J., Shanov, V.N., Yin, Z., Eds.; William Andrew: Oxford, UK, 2014; pp. 313-331.

14. Zucchelli, A.; Focarete, M.L.; Gualandi, C.; Ramakrishna, S. Electrospun nanofibers for enhancing structural performance of composite materials. Polym. Adv. Technol. 2011, 22, 339-349. [CrossRef]

15. Qian, H.; Greenhalgh, E.S.; Shaffer, M.S.P.; Bismarck, A. Carbon nanotube-based hierarchical composites: A review. J. Mater. Chem. 2010, 20, 4751-4762. [CrossRef]

16. Aluko, O.; Gowtham, S.; Odegard, G.M. Multiscale modeling and analysis of graphene nanoplatelet/carbon fiber/epoxy hybrid composite. Compos. Part B 2017, 131, 82-90. [CrossRef]

17. Xu, H.; Tong, X.; Zhang, Y.; Li, Q.; Lu, W. Mechanical and electrical properties of laminated composites containing continuous carbon nanotube film interleaves. Compos. Sci. Technol. 2016, 127, 113-118. [CrossRef]

18. Wang, S.; Downes, R.; Young, C.; Haldane, D.; Hao, A.; Liang, R.; Wang, B.; Zhang, C.; Maskell, R. Carbon fiber/carbon nanotube buckypaper interply hybrid composites: Manufacturing process and tensile properties. Adv. Eng. Mater. 2015, 17, 1442-1453. [CrossRef]

19. Su, Y.; Zhang, S.; Zhang, X.; Zhao, Z.; Jing, D. Preparation and properties of carbon nanotubes/carbon fiber/poly (ether ketone) multiscale composites. Compos. Part A 2018, 108, 89-98. [CrossRef]

20. Veedu, V.P.; Cao, A.; Li, X.; Ma, K.; Soldano, C.; Kar, S.; Ajayan, P.M.; Ghasemi-Nejhad, M.N. Multifunctional composites using reinforced laminae with carbon-nanotube forests. Nat. Mater. 2006, 5, 457-462. [CrossRef]

21. Zhou, H.W.; Mishnaevsky, L., Jr.; Yi, H.Y.; Liu, Y.Q.; Hu, X.; Warrier, A.; Dai, G.M. Carbon fiber/carbon nanotube reinforced hierarchical composites: Effect of CNT distribution on shearing strength. Compos. Part B 2016, 88, 201-211. [CrossRef]

22. Shin, Y.C.; Novin, E.; Kim, H. Electrical and thermal conductivities of carbon fiber composites with high concentrations of carbon nanotubes. Int. J. Precis. Eng. Manuf. 2015, 16, 465-470. [CrossRef]

23. Park, J.G.; Louis, J.; Cheng, Q.; Bao, J.; Smithyman, J.; Liang, R.; Wang, B.; Zhang, C.; Brooks, J.S.; Kramer, L.; et al. Electromagnetic interference shielding properties of carbon nanotube buckypaper composites. Nanotechnology 2009, 20, 415702. [CrossRef] [PubMed]

24. Silveira, D.C.; Gomes, N.; Rezende, M.C.; Botelho, E.C. Electromagnetic properties of multifunctional composites based on glass fiber prepreg and Ni/carbon fiber veil. J. Aerosp. Technol. Manag. 2017, 9, 231-240. [CrossRef]

25. Zhao, X.; Fu, J.; Wang, H. The electromagnetic interference shielding performance of continuous carbon fiber composites with different arrangements. J. Ind. Text. 2016, 46, 45-58. [CrossRef]

26. Sarkar, K.; Gomez, C.; Zambrano, S.; Ramirez, M.; de Hoyos, E.; Vasquez, H.; Lozano, K. Electrospinning to Forcespinning ${ }^{\mathrm{TM}}$. Mater. Today 2010, 13, 12-14. [CrossRef]

27. Akia, M.; Cremar, L.; Chipara, M.; Munoz, E.; Cortez, H.; de Santiago, H.; Rodriguez-Macias, F.J.; Vega-Cantú, Y.I.; Arandiyan, H.; Sun, H.; et al. In situ production of graphene-fiber hybrid structures. ACS Appl. Mater. Interfaces 2017, 9, 25474-25480. [CrossRef]

28. Cremar, L.D.; Acosta-Martinez, J.; Villarreal, A.; Salinas, A.; Wei, L.; Mao, Y.; Lozano, K. High-throughput of multifunctional carbon nanofibers from water soluble precursors. Chem. Fibers Int. 2016, 66, 40-42.

29. Vasquez, H.; Espinoza, L.; Lozano, K.; Foltz, H.; Yang, S. Simple device for electromagnetic interference shielding effectiveness measurement. IEEE EMC Soc. Newslett. 2009, 220, 62-68.

30. Al-Saleh, M.H.; Sundararaj, U. Electromagnetic interference shielding mechanisms of CNT/polymer composites. Carbon 2009, 47, 1738-1746. [CrossRef] 
31. Al-Saleh, M.H.; Saadeh, W.H.; Sundararaj, U. EMI shielding effectiveness of carbon based nanostructured polymeric materials: A comparative study. Carbon 2013, 60, 146-156. [CrossRef]

32. Song, W.-L.; Cao, M.-S.; Lu, M.-M.; Bi, S.; Wang, C.-Y.; Liu, J.; Yuan, J.; Fan, L.-Z. Flexible graphene/polymer composite films in sandwich structures for effective electromagnetic interference shielding. Carbon 2014, 66, 67-76. [CrossRef]

33. Farukh, M.; Singh, A.P.; Dhawan, S.K. Enhanced electromagnetic shielding behavior of multi-walled carbon nanotube entrenched poly (3,4-ethylenedioxythiophene) nanocomposites. Compos. Sci. Technol. 2015, 114, 94-102. [CrossRef]

34. Lee, S.-H.; Kang, D.; Oh, I.-K. Multilayered graphene-carbon nanotube-iron oxide three-dimensional heterostructure for flexible electromagnetic interference shielding film. Carbon 2017, 111, 248-257. [CrossRef]

35. Cremar, L.D.; Acosta-Martinez, J.; Villarreal, A.; Salinas, A.; Lozano, K. Mechanical and electrical characterization of carbon nanofibers produced from water soluble precursors. Mater. Today Commun. 2016, 7, 134-139. [CrossRef]

36. Chung, D.D.L. Materials for electromagnetic interference shielding. J. Mater. Eng. Perform. 2000, 9, 350-354. [CrossRef]

37. Gelves, G.A.; Al-Saleh, M.H.; Sundararaj, U. Highly electrically conductive and high performance EMI shielding nanowire/polymer nanocomposites by miscible mixing and precipitation. J. Mater. Chem. 2011, 21, 829-836. [CrossRef]

38. Ra, E.J.; An, K.H.; Kim, K.K.; Jeong, S.Y.; Lee, Y.H. Anisotropic electrical conductivity of MWCNT/PAN nanofiber paper. Chem. Phys. Lett. 2005, 413, 188-193. [CrossRef]

39. Arjmand, M.; Mahmoodi, M.; Gelves, G.A.; Park, S.; Sundararaj, U. Electrical and electromagnetic interference shielding properties of flow-induced oriented carbon nanotubes in polycarbonate. Carbon 2011, 49, 3430-3440. [CrossRef]

40. Chen, Z.; Xu, C.; Ma, C.; Ren, W.; Cheng, H.-M. Lightweight and flexible graphene foam composites for high-performance electromagnetic interference shielding. Adv. Mater. 2013, 25, 1296-1300. [CrossRef]

41. Zeng, Z.; Jin, H.; Chen, M.; Li, W.; Zhou, L.; Zhang, Z. Lightweight and anisotropic porous MWCNT/WPU composites for ultrahigh performance electromagnetic interference shielding. Adv. Funct. Mater. 2016, 26, 303-310. [CrossRef]

42. Ameli, A.; Nofar, M.; Wang, S.; Park, C.B. Lightweight polypropylene/stainless-steel fiber composite foams with low percolation for efficient electromagnetic interference shielding. ACS Appl. Mater. Interfaces 2014, 6, 11091-11100. [CrossRef]

43. Raagulan, K.; Braveenth, R.; Jang, H.J.; Lee, Y.S.; Yang, C.-M.; Kim, B.M.; Moon, J.J.; Chai, K.Y. Electromagnetic shielding by MXene-graphene-PVDF composite with hydrophobic, lightweight and flexible graphene coated fabric. Materials 2018, 11, 1803. [CrossRef]

44. King, J.A.; Pisani, W.A.; Klimek-McDonald, D.R.; Perger, W.F.; Odegard, G.M.; Turpeinen, D.G. Shielding effectiveness of carbon-filled polypropylene composites. J. Compos. Mater. 2016, 50, 2177-2189. [CrossRef]

45. Schulz, R.B.; Plantz, V.C.; Brush, D.R. Shielding theory and practice. IEEE Trans. Electromagn. Compat. 1988, 30, 187-201. [CrossRef]

46. Guo, Q.; Zhou, X.; Li, X.; Chen, S.; Seema, A.; Greiner, A.; Hou, H. Supercapacitors based on hybrid carbon nanofibers containing multiwalled carbon nanotubes. J. Mater. Chem. 2009, 19, 2810-2816. [CrossRef]

47. Engel, A.B.; Cherifi, A.; Tingry, S.; Cornu, D.; Peigney, A.; Laurent, C. Enhanced performance of electrospun carbon fibers modified with carbon nanotubes: promising electrodes for enzymatic biofuel cells. Nanotechnology 2013, 24, 245402. [CrossRef]

48. Weng, B.; Xu, F.; Salinas, A.; Lozano, K. Mass production of carbon nanotube reinforced poly(methyl methacrylate) nonwoven nanofiber mats. Carbon 2014, 75, 217-226. [CrossRef]

49. Chang, H.; Yeh, Y.-M.; Huang, K.-D. Electromagnetic shielding by composite films prepared with carbon fiber, Ni nanoparticles, and multi-walled carbon nanotubes in polyurethane. Mater. Trans. 2010, 51, 1145-1149. [CrossRef]

50. Jou, W.-S.; Cheng, H.-Z.; Hsu, C.-F. The electromagnetic shielding effectiveness of carbon nanotubes polymer composites. J. Alloys Compd. 2007, 434-435, 641-645. [CrossRef]

51. Luo, X.; Chung, D.D.L. Electromagnetic interference shielding reaching $130 \mathrm{~dB}$ using flexible graphite. Mat. Res. Soc. Symp. Proc. 1997, 445, 235-238. [CrossRef] 
52. Luo, X.; Chung, D.D.L. Electromagnetic interference shielding using continuous carbon-fiber carbon-matrix and polymer-matrix composites. Compos. Part B 1999, 30, 227-231. [CrossRef]

53. Das, N.C.; Khastgir, D.; Chaki, T.K.; Chakraborty, A. Electromagnetic interference shielding effectiveness of carbon black and carbon fibre filled EVA and NR based composites. Compos. Part A 2000, 31, 1069-1081. [CrossRef]

54. Yang, S.; Lozano, K.; Lomeli, A.; Foltz, H.D.; Jones, R. Electromagnetic interference shielding effectiveness of carbon nanofiber/LCP composites. Compos. Part A 2005, 36, 691-697. [CrossRef]

55. Thomassin, J.-M.; Pagnoulle, C.; Bednarz, L.; Huynen, I.; Jerome, R.; Detrembleur, C. Foams of polycaprolactone/MWNT nanocomposites for efficient EMI reduction. J. Mater. Chem. 2008, 18, 792-796. [CrossRef]

56. Mahmoodi, M.; Arjmand, M.; Sundararaj, U.; Park, S. The electrical conductivity and electromagnetic interference shielding of injection molded multi-walled carbon nanotube/polystyrene composites. Carbon 2012, 50, 1455-1464. [CrossRef]

(C) 2019 by the authors. Licensee MDPI, Basel, Switzerland. This article is an open access article distributed under the terms and conditions of the Creative Commons Attribution (CC BY) license (http://creativecommons.org/licenses/by/4.0/). 